\title{
Siluetas entintadas, instalación gráfica, life-writing gráfico y geografías corpóreas: Who Is Ana Mendieta?
}

Este ensayo examina la narración gráfica Who Is Ana Mendieta? (20II), de las artistas canadienses Christine Redfern and Caro Caron, como un biopic gráfico que conforma un discurso visual feminista de life-writing sobre la artista cubana Ana Mendieta (1948-1985). El artículo identifica como estrategia gráfica seminal el trazo de siluetas entintadas que esculpidas en forma fluida narran la vibrante vida artística de Mendieta, inscriben su estética de avanzada y registran su espíritu rebelde y el legado de su producción performativa e intermediática. Este biopic gráfico encarna un manifiesto contra la violencia de género y la narración gráfica deviene activismo entintado que reclama borraduras de la memoria cultural global.

Palabras clave: Ana Mendieta, artistas latinas, narración de vida postfeminista, biopic gráfico, cuerpos entintados, violencia de género

The essay examines the graphic narrative Who Is Ana Mendieta? (20II), by Canadian artists Christine Redfern and Caro Caron, as a graphic biopic which constructs a postfeminist life-writing visual discourse of the Cuban artist Ana Mendieta (1948-1985). The article identifies the ink drawings of bodies as the main graphic technique which carves fluid silhouettes to narrate Mendieta's vibrant artistic life, her daring aesthetics, her defiant spirit and courage, and the legacy of her performative and intermedia production. This graphic biopic embodies a manifesto denouncing violence against women, and the graphic narration becomes inked activism to reclaim the erasures of the global cultural memory.

Keywords: Ana Mendieta, Latina artists, postfeminist life-writing, graphic biopic, inked bodies, gender violence

La narrativa gráfica Who Is Ana Mendieta? (2OII), de las artistas canadienses Christine Redfern y Caro Caron, sobre la reconocida artista performativa, intermediática y experimental cubana Ana Mendieta (I948-1985), desmantela un cuerpo correccional ético-estético, genérico, sexual y 
artístico hegemónico dominante. El texto gráfico desentraña omisiones, borraduras y montajes discursivos sensacionalistas, tanto en relación a la exclusión de género de artistas femeninas, como en cuanto a la violencia de género, además de montar en escena distintas versiones sobre la muerte de la artista cubana. El situar la biografía gráfica como un género feminista postmoderno implica asumir este género epistemológico híbrido como una plataforma escritural que subjetiviza en sus ilustraciones la conformación de un sujeto femenino biografiado como sujeto histórico, fluido y des/colonizado. ${ }^{2}$

El filtro feminista de la guionista Christine Redfern en colaboración con el impulso artístico de la ilustradora Caro Caron destacan en su estética gráfica un pacto referencial que documenta líneas de vida del sujeto latino biografiado y desarticulan e interrogan de frente el control discursivo de la memoria cultural dominante de su momento. Ciertamente, esta narración gráfica poblada de siluetas entintadas tiñe desde un filtro feminista el perfil del sujeto latino en crudo, y pone en circulación: a) imaginarios grafiados; b) narrativas acalladas; y c) una documentación gráfica del provocador, intimidante y disidente arte escultórico medioambiental de Mendieta. El término siluetas entintadas opera en este ensayo como un significante flotante referencial múltiple que remite a la técnica gráfica de la ilustración, a la carga semántica de violencia de género, a la estética feminista incorporada al texto, a la metanarrativa estética de la artista cubana cavada en la biografía y al desenlace de su narrativa biográfica.

Nacida en Cuba, la artista Ana Mendieta asume el entorno cultural y político en el que se forma después de su exilio, abrazando en sus prácticas estéticas desde los setenta un atrevido e inédito arte intermediático escultórico-ambiental, performativo y fílmico de carácter experimental. Siendo una artista transcultural, transfronteriza e intermediática reconocida nacional e internacionalmente como artista performativa y visual, Mendieta imprime con su propia silueta un arte conceptual, performativo, transcultural, espiritual, genérico y político plasmado visceralmente en un cuerpo artístico en fuga desde 1987 . Su práctica estética se encarna en esculturas-tierra, instalaciones, performances o actuaciones, fotografías y filmes o videos cortos que documentan desde su cuerpo una obra efímera, evanescente y fugitiva. Una vasta producción visual que incluye su arte-acción, arte-objetos y bosquejos de proyectos, notas inéditas, además de sus esculturas rupestres esculpidas en Cuba, traza su trayectoria de casi trece años como una práctica estética performativa y corpórea en proceso hasta su muerte en 1985.

Mendieta hace de su cuerpo la materia prima, el lenguaje y el sitio-habla de su propuesta estética de dis/locación, desestabilización y exilio. Usa su 
corporeidad como un molde orgánico, simbólico, medioambiental en disolvencia, dejándonos ver las huellas y los sitios-habla de su des/territorialización. Su Serie Siluetas, formada por piezas esculpidas con tierra, fuego, aire y agua, rocas, humo y sangre, sintetiza geografías corpóreas medioambientales que definen su práctica estética inquieta desde los setenta en distintos sitios geográficos en México, Estados Unidos, Cuba y Europa. A más de cuarenta años, su arte nomádico revela una propuesta estética arriesgada, como denota su archivo en la Galería Lelong en Nueva York, representante de la producción artística de Ana Mendieta desde r991 y organizadora de su inventario en r998-99. Enfatizando el carácter intermedial, visual y performativo de la obra de Mendieta, su más reciente exhibición y el catálogo del mismo nombre Covered in Time and History: The Films of Ana Mendieta (2015) documentan visualmente siluetas de sí misma, esculturas-medioambientales, instalaciones performativas y procesos conceptuales fundiendo cuerpo, tierra y arte en una estética documental, fotográfica y postcolonial en donde forja su propio lenguaje identitario híbrido entre culturas y géneros y entre corporeidad, paisaje y desterritorialización, temporalidades, memorias e historias inacabadas.

Desde una práctica de lectura del biopic posmoderno femenino como práctica discursiva alternativa que diseña el perfil biográfico en relación a poder, vigilancia represiva de su contexto histórico-cultural y resistencias del sujeto biografiado, Redfern y Caron articulan sediciosamente el acto de entintar como estrategia gráfica. Su ejecución discursiva conforma "nuevas áreas de indecibilidad", agita al lector-espectador al signar el relato con marcadores identitarios desde un entintado de género y des/centra al sujeto entre "huellas, rastros, inscripciones" y singularidad en una cartografía expresada desde la subjetividad contemporánea (Arfuch, El espacio biográfico I7-I8). De esta forma, como táctica discursiva indócil que se hace patente en la piel del texto gráfico, sus protagonistas entintados son colocados en el relato entre macroviñetas y se les ubica estratégicamente en escenarios-instalaciones secuenciales gráficas frente a personajes situados en una espacio-temporalidad significativa en el relato de vida. El acto de teorizar sobre el biopic gráfico en Who Is Ana Mendieta? demanda la consideración crítica de un entintado de género que opera en el relato como armazón estructural, como textura híbrida y performativa del discurso ilustrado y como destreza gráfica que acentúa el tono agitador del basamento referencial del sujeto biografiado.

Como indica la crítica cultural argentina Leonor Arfuch en El espacio biográfico: dilemas de la subjetividad contemporánea (2002), el relato biográfico implica no solo considerar "la disposición de acontecimientos históricos o ficcionales - en un orden secuencial, o una ejercitación 
mimética", del "registro de la acción humana, con sus lógicas, personajes, tensiones y alternativas, sino [que remite] a la forma por excelencia de estructuración de la vida y por ende, de la identidad", transcultural e intermedial en un modo de producción cultural visual (88-89). Este entintado en términos gráficos signa el acabado de imágenes, los contornos y rellenos de la narrativa de life-writing, el diseño de los protagonistas, la densidad de la ambientación y la espacio-temporalidad y situacionalidades de las autoras, protagonistas y lectores gráficos. A su vez, esta técnica de ilustración entintada moldea metadiscursivamente réplicas del arte original e icónico de Mendieta en selectas macroviñetas en diversas microescenas como su Serie Siluetas desparramada a través del relato. En este sentido, el teñido biográfico de carga simbólico-cultural, étnica y genérica demanda un consumo de lectura a partir de entintados de género que inundan relatos, historias, testimonios, documentos y memorias culturales sobre la artista cubana, además de incorporar borrados libretos de vida de cuantiosas artistas del imaginario cultural hegemónico. 3

La reconocida curadora, crítica y activista Lucy R. Lippard introduce el relato de life-writing gráfico en un ensayo personal "Who Is Ana Mendieta/ Nobody Else", sobre la artista cubana, donde comparte el momento íntimo de escuchar por la radio la noticia de la trágica muerte de la artista, y menciona el homenaje público que organizó en el Centro de Relaciones Inter-Americanas, describe su conmovedor entierro en Iowa y define el estado de polarización del mundo del arte neoyorquino a raíz de la acusación del asesinato y del doble juicio de su marido Carl Andre, quien fue exonerado. Lippard afirma que nunca se podrá contestar la pregunta Who Is Ana Mendieta? y reconoce el relato gráfico de Redfern y Caron como una denuncia mordaz contra la violencia de género, como una forma de activismo y como un texto de insurrección que se arraiga en la tradición de las fotonovelas latinoamericanas y de los cómics femeninos de los sesenta. Comenta su propuesta estética en proceso, sus ideas políticas e ideología, su cubanidad, sus viajes a Cuba, entre i980 y 1983, el peso del desarraigo, sus excesos, el pulso de su furia y su intenso aislamiento, mientras resalta la forma en que hizo de su propio cuerpo materia prima de un proceso de autodescubrimiento, auto-afirmación y exorcismo ante el dolor de la desterritorialización (Lippard I2-I3). La crítica destaca su inquisitiva inteligencia, su inquietud estética, la honda búsqueda de sí misma, su pasión e ímpetu, convicciones y quemante energía, sin dejar de nombrar su vulnerabilidad. Concluye afirmando que la muerte de Ana Mendieta representa simbólicamente a miles de mujeres violentadas a pesar de décadas de lucha feminista, signando referencialmente crímenes sociales y 
violencias de género que urgentemente claman por ser interrogadas (Lippard I4).

Al testimoniar que los crímenes de género no han sido resueltos como evidencian los feminicidios de las mujeres de Juárez, México, Lippard destaca que la narración gráfica como género opera como herramienta crítica directa que manifiesta en su espesor la furia e indignación femenina ante la violencia doméstica y la violencia de género, e insiste en que las denuncias de género de carácter visual cumplen la función de vengar profundas pérdidas de figuras femeninas como la que sintetiza la artista cubana (15). ${ }^{4}$ Por su parte, Christine Redfern identifica a Ana Mendieta como una de las videoartistas más prolíficas de los setenta, quizás la artista cubana más conocida a nivel global en el siglo XXI, y declara convincentemente que su narración gráfica no solo defiende el arte de Ana Mendieta, sino que también deliberadamente materializa la toma de conciencia del vacío y de la ausencia de su producción artística, como sucede con el cuerpo artístico de tantas otras figuras del arte femeninas (Redfern y Caron 40).

PODER GRÁFICO ENTINTADO, SECUENCIALIDAD CONDENSADA Y GESTUALIDAD GARIGOLEADA

El poder evocativo de Who Is Ana Mendieta? se fundamenta en el trazo gráfico entintado, se asienta en un guion de vida con conciencia, se cimienta en un fino manejo del deslizamiento oculocéntrico del lector gráfico entre bordes de viñetas movedizas. El lector-espectador transita entre macroviñetas y microviñetas matizadas por sus acabados en detalle, ilustraciones garigoleadas hiperrealistas, economía de palabras, hibridez intermediática y ubicuidad móvil del lector implícito. El relato de life-writing orienta al lector gráfico sobre teorías de conocimiento, performatividad textual, construcción y diseño ilustrado del sujeto latino, memoria colectiva, contexto estético y legado cultural. Este biopic gráfico agita y sondea la conciencia del lector sobre prácticas de representación y de auto/representación relacionales, contextuales, espaciales y temporales del sujeto construido frente a omisiones, nulidades, indiferencia y borraduras de la historia personal de la artista (Smith y Watson, "Mapping" 6, IO-II). La narración visual entreteje una textura conceptual y afectiva encarnada en la corporeidad panlatina de Mendieta entre mestizajes formales, conceptuales, culturales y estílisticos y recalca su geografía interior entre líneas de vida en fuga de su arte performativo. ${ }^{5}$

La narración biográfica se consolida en una condensación y síntesis de vida magistral, en la secuencialidad asintótica y palimpséstica de las macroviñetas, la exactitud del acabado en detalle de cada una de las 
ilustraciones y la pulida gestualidad de los protagonistas en escena. El relato visual puntualiza, aquilata y abre los pliegues del discurso de life-writing en su trazo con tinta escurridiza hacia dentro y hacia fuera del texto gráfico. Redfern y Caron prensan en el biopic una escritura gráfica entintada en profundidad y en expansión en un texto palimpséstico, puntuado sintácticamente entre secuencias, marcas, marcadores y huellas biográficas del sujeto femenino transfronterizo (2I-22, 33). El discurso de life-writing gráfico como práctica epistémica feminista incorpora la densidad de un arte corpóreo performativo entre siluetas de Mendieta en dispersión y ensambla una galería con retratos de figuras del arte femeninas como acusación y protesta por sus ausencias y borraduras en el mundo artístico.

TEORÍA DE LIFE-WRITING, INTERMEDIALIDAD Y ARTE GRÁFICO ENTINTADO

La teoría de la narración gráfica, intermedialidad, género y sexualidades, corporeidad y life-writing sitúan Who Is Ana Mendieta? como biopic gráfico postfeminista. Dicho discurso de life-writing se construye desde una subjetividad situada, una re-articulación narrativa alternativa, la sedimentación de elementos intermediales y genéricos diversos, montajes gráficos híbridos hechos de residuos y fracciones del pasado inundando el presente y del presente invadiendo el pasado que desmantelan premisas biográficas hegemónicas masculinas (Polaschek I64). ${ }^{6}$ Este relato como instalación gráfica entintada de carácter performativo desafía prescripciones de género misóginas, una narración cronológica lineal, una representación biográfica reduccionista, la falta de valoración de su legado artístico, y muestra relatos parciales, fabricados, tendenciosos y escandalosos sobre Mendieta. Como indica Michael Lackey, editor de un volumen especial sobre bioficciones postmodernas de $a / b$ : Auto/Biography Studies (2016), la dramatización intermedial de un sujeto biografiado, aunque parezca una imposibilidad en sí misma en términos de representar toda una vida, encarna textualmente al sujeto desde una verosimilitud y referencialidad subjetivizada postmoderna (8). La práctica gráfica de Redfern y Caron documenta subjetivamente la narración de vida de un sujeto histórico referencial al inscribir una reinterpretación ilustrada de un constructo bio/gráfico interseccional, literario-cultural y político desde marcos interpretativos fluidos y contestatarios, "pensando el cuerpo pensando en el cuerpo social y viceversa" (Smith 70).

Como indican Miriam Fuchs y Craig Howes en Teaching Life Writing Texts (2008), las tecnologías comunicativas contemporáneas producen modalidades socio-políticas y genéricas contestatarias de manera que la producción crítica y teórica significativa reciente sobre género, raza, orientación social, clase, discapacidad, estatus de comunidades indígenas, 
políticas y estéticas postcoloniales se concentra en textos auto/biográficos que, como Who Is Ana Mendieta?, arraigan identidad, subjetividad, memoria, agencia, historia y representación (I). Como declara la crítica Gabriele Helms en su lúcido ensayo sobre la inestabilidad de los géneros de lifewriting contemporáneos canadienses, estos nunca son "neutrales ni ahistóricos", sino que se constituyen como géneros discursivos ideológicamente "cargados" ya que encarnan cosmovisiones, valores y actitudes mediatizados (IOO). Añade que estos géneros nunca consiguen registrar la experiencia humana de forma transparente ya que en su articulación y materialización estos siempre se constituyen discursivamente y enfatiza la intencionalidad del uso del lenguaje y de la forma narrativa del relato de la vida elegida (Helms ioo). Afirma que la narración de vida siempre se mediatiza al inscribirse las líneas de vida de un sujeto en forma gráfica. En su opinión, las convenciones genéricas del life-writing gráfico ubican la experiencia del sujeto representado frente a complejidades del relato performativo de manera que formas audaces y contestatarias quiebran límites de género, habitan espacios blancos y recalcan convenciones discursivas desde interseccionalidades, dentro de contextos histórico-culturales situados (IOO-O3).

Como práctica postmoderna interdisciplinaria este discurso afianza la agencia interpretativa del lector gráfico sobre el conocimiento de la vida y muerte de la destacada artista cubana al definir como punto de partida y centro de gravedad del relato visual su legado estético experimental armado desde un filtro de género, transcultural, étnico, ideológico, transfronterizo y global. Como señalan las editoras Laurie McNeill y Kate Douglas en su ensayo introductorio a Teaching Lives: Contemporary Pedagogies of Life Narratives en $a / b$ : Autobiography Studies (2017) el valor pedagógico de leer, escribir y producir life narratives radica en forjar un pensamiento crítico sobre subjetividad e intersubjetividad, impulsar un debate acerca de la representación del sujeto biografiado e identificar marcadores experienciales e interseccionales. Desde su campo interpretativo, estos discursos desde sitios enunciativos desde los que se producen y consumen, cuestionan epistemología, narratividad y verosimilitud potenciando la agencia de los sujetos lectores que se aproximan a estos desde el conocimiento de que son narrativas modeladas ideológicamente, construidas socialmente y limitadas contextualmente, en términos culturales e históricos (McNeill y Douglas 7). Por su parte, la crítica Jennifer Drake en Teaching Lives: Contemporary Pedagogies of Life Narratives propone que este género innovador contemporáneo agita la piel del texto gráfico en formas inusitadas, mientras agudiza el sentido de dislocación del lector visual. Declara que las estrategias del discurso gráfico retan al 
consumidor de una narración de vida a pensar críticamente sobre posicionalidades, efectos especiales, registros multimodales y marcadores diferenciales desde su campo interpretativo (Drake 7r).

El diseño gráfico del texto postfeminista Who Is Ana Mendieta? inscribe el perfil de la artista cubana siendo niña-adolescente-universitaria-artista, estudiante graduada del Programa Intermediático de la Universidad de Iowa, creadora de siluetas-esculturas en México, Estados Unidos y Cuba, y productora de cerca de cien filmes experimentales de su obra, exhibiéndose recientemente 2I películas, mientras el resto quedan en proceso de ser editadas (Lukkas y Oransky i8). El bosquejo biográfico despliega su geografía estética al insertar estratégicamente sus esculturas arte-tierra en secuencias que arman un relato performativo sobre su práctica artística efímera, precaria, transitoria y fugaz. El texto pone en escena sitios gráficos que capturan su incursión en la escena de galerías neoyorkinas, debates y obsesiones estéticas y performativas, la entrega del prestigioso Premio de Roma (1983) y su turbulenta relación conyugal con el artista minimalista Carl Andre, que culminó en la muerte de Mendieta el 8 de septiembre de 1985. Redfern y Caron forjan un biotexto gráfico persuasivo al insertar provocativamente sus intervenciones artísticas, siluetas-esculturas-tierra entintadas y documentar su arte experimental y evanescente desde los años setenta hasta su muerte. El guion de Redfern y las ilustraciones garigoleadas, neobarrocas e hiperrealistas de Caron y de Redfern componen una biografía gráfica singular al resaltar su perfil como un sujeto-artistalatino cuya propuesta estética la sitúa como una de las artistas iconoclastas de mayor creatividad y crudeza original en el siglo XX, tal como lo evidencian los seminales estudios monográficos de la curadora y crítica Olga Viso sobre sus esculturas-tierra, su arte performativo, la documentación fotográfica, el archivo personal y su estética en proceso.

GEO/GRAFÍAS, CORPOREIDADES Y DIÁSPORAS EN UN GÉNERO DE LIFE-WRITING El diseño del relato gráfico de Redfern y Caron como práctica genéricocultural alternativa cuestiona la hegemonía del mundo del arte al desestabilizar crudamente paradigmas contestatarios sobre ausencias, silencios, e invisibilidades sobre la obra artística y la vida de Ana Mendieta fuera del museo, de la galería y/o del archivo de la memoria cultural. La práctica intermedial asumida por ambas autoras en este texto gráfico hace patente su intervención, intencionalidad, e interferencia al desatar los nudos de identidades nomádicas del sujeto femenino biografiado y confrontar al lector gráfico ética, estética, cultural, étnica y políticamente. Subjetivizando representaciones en competencia entre imágenes e ilustraciones referenciales, ambas autoras materializan una serie de 
encuadres histórico-culturales y genéricos al producir escenas multimodales. El cuerpo-texto gráfico entintado Who Is Ana Mendieta? entreteje una narratividad biográfica que desde nuestra interpretación de la teoría de la memoria y life-writing de la crítica Leonor Arfuch conforma un discurso con "modos diversos en que se inscribe la huella traumática de los acontecimientos en los destinos individuales," incluyendo fragmentos de vida desde "claves interpretativas de una subjetividad situada, tanto en términos estéticos como éticos y políticos," (Memoria y autobiografía i4) en casi 20 macroviñetas que incorporan escenas de circunstancias perturbadoras sobre la trágica muerte de Mendieta, el juicio de Carl Andre y su exoneración. El texto gráfico explora narraciones incompletas, testimonios circunstanciales, noticias escandalosas y documentos legales y jurídicos sobre el caso, además de entrevistas, crónicas breves periodísticas e información archivada o inaccesible en el apartado "Blind Spot: A Note to Readers", colocado al final del relato (Redfern y Caron 39-53).

Además de insertar tácticamente en el texto visual una muestra de obras icónicas de Mendieta como el acto de performance de la violación (I973), una selección de sus siluetas-tierra-esculturas, la creación de esculturas rupestres en Cuba, e inclusive una silueta icónica hecha en México que irónicamente remite a su muerte trágica, Redfern y Caron desmantelan formaciones textuales, interreferenciales e intermediáticas del libreto biográfico canónico. Provocan su desplome frente al lector gráfico ya que ambas autoras des/centran marcos de referencia auto/biográficos desde la des/composición, des/integración y disolvencia del género biográfico hegemónico, desatan resistencias en escenas, y generan en sus bordes gráficos una explosión de significantes que asaltan la conciencia del lector, al nombrar a Mendieta desde su cuerpo gráfico entintado.

La crítica de arte y guionista y la ilustradora producen una narración de vida en una veintena de macroviñetas desplegadas visualmente como instalaciones gráficas con exuberancia, excentricismo y excedentes sintácticos y semánticos (Redfern y Caron 40). Sus focalizaciones móviles incorporan a un narrador omnisciente, una narradora auto/biográfica personal y narradores-protagonistas que habitan distintas macroviñetas. Ambas crean microescenas performativas que suplen diferentes temáticas, argumentos, sujetos-protagonistas, entornos y espacio-temporalidades y revelan historias, momentos y críticas feministas sobre la marginación de Mendieta y de muchas otras artistas (Redfern y Caron 4I-44). El relato bio/gráfico engarza narrativas independientes que agilizan líneas interpretativas en fuga, arman escenas de vida y de muerte en papel y registran la intervención performativa icónica de Ana Mendieta como se 
observa en Sin título y en Escena de la violación de 1973, entre otras (Redfern y Caron 48) .

El texto bio/gráfico acentúa trayectorias político-culturales y de género de la protagonista, provoca una estética de agitación y disidencia, crea centros de gravedad gráfica dispersos entre líneas de vida y monta irónicamente contextos hegemónicos. El relato gráfico nos remite a la conflictiva relación conyugal, conflictos maritales e interrogación crítica del proceso judicial que exoneró del crimen a su esposo Carl Andre en I988, además de mostrar las protestas post-mortem frente al Museo Guggenheim y la manifestación-acción de Guerillas Girls reclamando contra la ausencia de Ana Mendieta en el Museo, en contraste con la presencia artística de Carl Andre. Como afirma Redfern en su ensayo corto en la segunda parte de la narración "Blind Spot: A Note to Readers", al preludiar el apartado periodístico experimental, muchos quisieran ignorar la vida y las circunstancias de la muerte de Ana Mendieta por la forma en que mancha la escena de la torre de marfil del arte contemporáneo y quizás preferirían mantener la idea de que el arte se sostiene por sí mismo, pero no se puede negar el hecho de que el arte se arraiga en nuestra identidad y experiencia de vida (Redfern y Caron 39).

Redfern y Caron cimientan un armazón de resistencia feminista en una narración biográfica desestabilizadora con la inserción de la producción artística de Mendieta y desmantelan convenciones representacionales de lo que denominamos un biopic gráfico. Ambas coautoras desnivelan narrativas, materializan discursos auto/bio/gráficos y acentúan el espesor de género y al abrazar prácticas culturales alternativas incorporan ópticas diferenciales y encarnan tácticamente en su diseño gráfico un imaginario biográfico feminista. Su libreto de life-writing construye un cuerpo-texto gráfico entintado entre secuencias interseccionalizadas que forjan una narrativa híbrida de sello performativo. Su condensación y síntesis del libreto de vida de la artista cubana, una selección de biografemas que cartografían el cuerpo biográfico de la artista desde una valencia de género y una estructura metonímica en cada macro y microviñeta, remiten correlacionalmente a otros microescenarios contextuales movedizos entintados que circulan, se intersecan, e inclusive dialogan entre macroviñetas y se desbordan fuera del texto (Redfern y Caron 24-25). Ambas autoras ponen en práctica estratégicamente una serie de técnicas de ilustración y diseño del life-writing que signan este texto insurrecto en la construcción de su relato biográfico como se observa en: a) el diseño de macro y microviñetas movedizas; b) el acabado gráfico entintado; c) los enmarcamientos y encuadres en correlación entre secuencias narrativas; d) la intermedialidad de otros discursos; y e) un espesor gráfico contestatario. 
INTERROGAR LA MEMORIA CULTURAL-GENÉRICA: ACTOS ENUNCIATIVOS, VOCES DISIDENTES, SUBJETIVIDAD(ES) FLUIDA(S)

Como destaca la crítica cultural del género gráfico femenino, Hilary L. Chute en su Graphic Women: Life Narrative and Contemporary Comics (2010), estas historias ilustradas frecuentemente encarnan lo traumático en forma intermediática, abrazan el desafío de lo no representable, resisten la victimización y empoderan sujetos ante la invisibilidad o ausencia. Who Is Ana Mendieta? incita al lector gráfico a visualizar sujetos pensantes, sujetos sexuados y sujetos disidentes dentro de la cultura hegemónica dominante y le hacen consciente de lo decisivo que es el enmarcamiento de una narración y de las formas en que éste afecta lo representado en el relato gráfico (Chute 2). En Who Is Ana Mendieta?, cada macroviñeta encuadra en el interior de su moldura gráfica en segmentos-montajes de planos sobrepuestos y origina actos de lectura elípticos, movedizos y asintóticos, que nos hacen circular correferencialmente alrededor de protagonistas en una misma microviñeta, $\mathrm{y}$, en otro nivel gráfico, movilizan nuestro tránsito entre escenarios gráficos de distinta relevancia biográfica, como se observa en la macroviñeta de la primera exhibición de Mendieta en una galería de Nueva York en I978 (Redfern y Caron 3I). Estas microviñetas enmarcadas dentro de otras macroviñetas operan como unidades independientes y despliegan garabatos gráficos como globos, letreros, carteles, rellenos entintados, líneas de grueso espesor, expresiones onomatopéyicas, espacios blancos y otros detalles gráficos configurando centros de gravedad movedizos. ${ }^{7}$ Los montajes de este cuerpo-texto bio/gráfico inacabado, incompleto y en dispersión, documentan violencias de género en el mundo artístico entre los cincuenta y los setenta, La Habana revolucionaria y postrevolucionaria de los sesenta y ochenta, escenarios culturales de protesta estadounidenses durante los sesenta y paisajes-tierra en Estados Unidos, Cuba y México, además de Nueva York como centro artístico icónico.

Los montajes de distintos tamaños, volumen, composición, naturaleza intrincada, ondulada y ensortijada generan planos disímiles, movimientos elípticos e isotópicos, e imponen tonos fluidos, elípticos o inconclusos, mientras registran espacialmente señas referenciales que suplementan otras marcas identitarias del relato bio/gráfico (Redfern y Caron I8-I9). Esta textura gráfica encarna una estética performativa entre sitios-simbólicos, sedimentos narrativos y escenarios-instalaciones gráficos del mundo del arte como se observa en la macroviñeta en la que Ana Mendieta discute su arte-tierra, representa su contribución al Programa Intermediático de la Universidad de Iowa y relata la relación íntima con su profesor y amante Hans Breder (I935-20I7), desde su arte producido en México (Redfern y 
Caron 47-49). Rótulos y globos movilizan tácticamente las líneas narrativas en dispersión entre bordes de una macroviñeta tripartita en la que afirma su pasión-obsesión por el arte, ofrece detalles biográficos y abraza confesiones de su vida íntima (Redfern y Caron 29). Las líneas de vida incorporan diversas geografías que inclusive sitúan a Mendieta en México, mientras crea sus siluetas o esculturas-tierra, o reproducen su figura icónica montando un esqueleto entintado en la portada de Who Is Ana Mendieta? Esta silueta de Mendieta deviene un motivo icónico que se hace presente en encuadres espacio-temporales, reproducciones de su arte y referentes gráficos que se materializan en cuatro esqueletos distintos y empoderan a Mendieta como sujeto-artista latino, experimental y performativo.

La superficie gráfica bosqueja entornos literales, metafóricos y figurativos y delinea una gestualidad distinta en cada una de las siluetas, de manera que arraiga la figura de Mendieta en el relato biográfico mientras documenta gráficamente su arte-escultural medioambiental como atestigüan las siluetas en "Blind Spot" tituladas Imagen de Yagul (1973), Gunpowder Silueta (198I), Death of a Chicken (1973) y Silueta sin título (I98I) (Redfern y Caron 47). Otra macroviñeta inscribe su panculturalismo, panafrolatinidad, afrocubanidad y otros mestizajes, mientras se desdobla en dos planos que refuerzan la visibilidad de una producción de siluetas en fuga. Así, el hecho de entintar marcadores biográficos del sujeto latino en dos columnas remite a distintas técnicas que realzan mestizajes culturales de sus esculturas-tierra, como sucede al enmarcar determinadas siluetas dentro de un ensanchado globo como son sus siluetas-tierra cubiertas de flores y clavos o Silueta de Ixtael que incorporan herencias prehispánicas o egipcias (Redfern y Caron 32).

Al darle al relato un tono gótico con el entintado, esta documentación gráfica de su obra, el retrato biográfico condensado, testimonios visuales y referencias subjetivizadas, arman las escenas últimas de la vida de Mendieta. De esta forma, las secuencias finales inscriben visceralmente un cuerpo golpeado que ahueca el techo de una deli en un rascacielos en Nueva York mientras se percibe entintada una silueta amortajada y ensangrentada, con un gran corazón sobre el pecho, silueta que se correlaciona con una silueta de 1973 que irónicamente parecería prefigurar su violenta muerte (Redfern y Caron 35).

La macroviñeta de la exhibición de su arte en Nueva York interseca secuencialmente dos escenas que exponen un panel entre artistas, críticos y audiencia enmarcados por las siluetas-esculturas-tierra de Mendieta exhibidas en una galería. La performatividad gráfica en la parte superior de esta macroviñeta muestra un rótulo pequeño al lado izquierdo que fecha el evento, enfatiza que es la primera exhibición de arte de Mendieta en Nueva 
York y se conecta con otra microescena en la parte inferior donde algunos globos revelan un sonido onomatopéyico desde las siluetas colgadas en la galería. Una manta en la parte superior de la macroviñeta anuncia el tema del panel sobre el movimiento de arte femenino y las actitudes artísticas masculinas mientras un globo de notable tamaño encierra el pensamiento de un crítico que acusa a Mendieta de crear un arte narcisista (Redfern y Caron 3I).

La figura de este personaje hablando con otros críticos dentro de la galería identifica su crisis de identidad y expresa en voz alta opiniones sobre la famosa y radical instalación feminista de Judy Chicago, "The Dinner Party" (1974-1979). En esta microescena, algunos globos pequeños ilustran las reacciones de algunos críticos, "Oooo HHH! Demasiadas vaginas", "Puro arte melodramático", "Primordialmente biológico...", "explosivamente un drama sensual" en la galería (Redfern y Caron 31). La complejidad del armazón deja entrever técnicas cinemáticas en el discurso gráfico como son una toma panorámica de la galería y acercamientos visuales hiperrealistas a la gestualidad detallada de críticos y artistas que los hace reconocibles como Nancy Spero (1926-2009), Carl Andre (1935-) y la misma Ana Mendieta (19481985).

En la macroviñeta "La gente vs. Carl Andre", Redfern y Caron incorporan la acusación del crimen en segundo grado del artista minimalista, su proceso judicial de 1985-1988 y su exoneración en I988. Ilustran en un panel de una sola página la figura de Andre por encima de un juez, mientras el juez clama en un globo, "La evidencia no me ha satisfecho más allá de una duda razonable" (Redfern y Caron 37). En otro sitio discursivo, se incorporan nueve microviñetas rectangulares y cuadradas de distinto tamaño donde se lee "Más arriba el cuerpo de Ana", señalando una flecha al piso 34. El lector visualiza el encuentro de la policía con Andre después de la caída de Mendieta desde el piso 34 del apartamento, capta su urgencia por lavarse las manos y ve dentro de la escena, una calavera con las manos ensangrentadas que tiñen su rostro con gotas de sangre. Otra microviñeta captura desde distintos ángulos una ventana abierta, un colchón contra la pared y otro tirado en el piso, botellas desparramadas por doquier, una silla caída y Andre lavándose las manos bajo la mirada a distancia de un policía que entra al apartamento (Redfern y Caron 36).

Un esmerado acabado en la última escena bio/gráfica que narra la muerte de Ana Mendieta resalta el nombre de la calle Waverly, dos policías tocando a la puerta, el viento helado colándose por la ventana abierta y la figura de Andre con el ceño fruncido, apurado lavándose las manos. Otro detalle del terminado gráfico de gran poder evocativo, simbólico y figurativo se advierte claramente en el arañazo en la frente de Andre que, como huella 
palpable y evidencia corpórea del contacto físico con Ana Mendieta la noche de la tragedia, se asoma como índice biográfico en cuatro viñetas diferentes (Redfern y Caron 36).

Una de las destrezas gráficas más eficientes de esta narración es el diseño mismo de veinte macroviñetas compuestas de microescenas en movimiento, empalmadas, fluidas y correlacionadas que denuncian brutalmente la violencia de género. Otra técnica gráfica de profundo efecto estético y afectivo se manifiesta en reproducciones de esculturas-tierra, siluetas y actos performativos de Ana Mendieta que articulan una metanarrativa mientras hacen palpable su pensamiento conceptual. La forma de ubicar al lector gráfico consolida otra estrategia visual notable al colocar su mirada al interior de una macroviñeta donde la artista ejecuta su performance del crimen sexual filmado por una cámara, mientras la metanarrativa incita a teorizar sobre el cuerpo entintado. En otro plano al interior de la escena, la artista cubana denuncia la violencia de género crudamente en un globo, "Mi hermana fue golpeada por su marido. Otra estudiante fue violada y asesinada en mi campus. Este acto de performance lo hice para denunciar crímenes de violencia sexual" (Redfern y Caron 28; énfasis añadido). El activismo gráfico remite correferencialmente a la figura de Mendieta como víctima de la violencia de género, dándole al texto un espesor biográfico que se amplía entre microescenas. El montaje del lifewriting en macroviñetas pone en escena ante el lector gráfico, no sólo hechos, momentos, trama, clímax y desenlace, sino un debate feminista sobre violencia doméstica, criminalidad sexual y una documentación plástica, videográfica y performativa feminista (Redfern y Caron 28).

ESCRITURA ENTINTADA, ACABADO GRÁFICO Y ENGLOBADOS PERTURBADORES La técnica del acabado gráfico refinado, preciso y artero que ilustra cada macroviñeta hace patente la complejidad conceptual, performativa y gráfica de las autoras canadienses, quienes insertan tácticamente al centro de la macroviñeta un globo con la imagen hiperbólica de Ana Mendieta temblando de miedo, secuestrada por la mano gigante de un gran esqueleto que invade el cuarto del performance del crimen sexual (Redfern y Caron 28). Esta microescena circular, englobada y entintada, en la parte inferior de la macroviñeta se relaciona con otras por medio del trazo del brazo de Mendieta en el centro del escenario, además de sedimentar otros relatos que desbordan los márgenes gráficos. Otra apreciable técnica del terminado de su ilustración radica en comentarios críticos e irónicos sobre la discriminación de género en el mundo del arte hegemónico. De esta forma, macroviñetas secuenciales arman la geografía biográfica de Mendieta y agregan al relato testimonios feministas sobre Carolee Schneemann y 
referencias gráficas a la rareza y excentricidad que estigmatizaron a Camille Claudel, Frida Kahlo, Emily Carr, Marie Bashkirtseff y Hubertine Auclert, entre otras (Redfern y Caron 24-27, 38, 44-46).

Ambas artistas canadienses generan una escritura gráfica entintada audaz, experimental $\mathrm{y}$ atrevida en montajes composicionales interseccionales en cada una de las páginas, valiéndose de unidades mínimas de segmentos biográficos movedizos. En su propuesta estéticogenérica formal, conceptual y composicional, arman un cuerpo-texto biográfico desde la transgresión, desmesura y exceso de tinta sobre la pielpapel del texto gráfico seleccionando índices biográficos fugitivos que rechazan identidades fijas de un cuerpo-texto entintado que politizan. El libreto de vida de Mendieta interseca biografía, género, desterritorialización y geografía étnico-cultural artística incitando a considerar el discurso gráfico del life-writing. Su arte corpóreo, performativo y escultóricoambiental, el ensayo intermedial de Christine Redfern "Blind Spot: A Note to Readers" y el último apartado sobre el fin de la vida de Ana Mendieta cuestionan materialización, representación y puesta en escena, mientras la portada captura a Mendieta montada en un esqueleto que opera como leitmotif a lo largo del relato gráfico. La geografía referencial y la réplica gráfica de una selección de su obra y de su producción escultórica, performativa y fílmica, además del hilo referencial que atraviesa el texto nombrando fuertemente la violencia de género, quedan enmarcados en las contraportadas que deslizan la mirada del lector gráfico sobre una galería ilustrada.

La intermedialidad como técnica estructurante del relato que se instaura desde la primera parte de la narración biográfica y en el apartado "Blind Spot: A Note to Readers" genera múltiples referentes que apuntan hacia afuera del relato y subrayan la naturaleza fluida del texto. Medios, cultura material, transposiciones, interferencias y huellas gráficas sedimentan una superficie gráfica que articula una lógica secuencial narrativa en expansión al circular por los encuadres residuos biográficos sobre la artista cubana.

Esta narración relacional, contrapuntística, oposicional, elíptica y nómada hace suyas errancias identitarias y ubica a Mendieta en contextos aleatorios que ponen en escena un life-writing disidente. La narración se sirve de singulares modalidades enunciativas, posicionalidades movedizas de protagonistas y lectores gráficos y un entintado gráfico que da espesor y densidad a los elementos narrativos mientras asalta la mirada del lector. El sello estílistico garigoleado, neobarroco y neoexpresionista de Caro Caron recalca trazos, rellenos y acabados en cada escena y en cada silueta entintada entre líneas, figuración y ambientación escénica ilustrada. 
GEOGRAFÍA GRÁFICA DE UN ARTE SECUENCIAL MOVEDIZO

Las secuencias bio/gráficas inscriben la obsesión estética-performativa, intermediática y disidente de Mendieta, abarcando desde los setenta hasta I985 en la narración gráfica. Comprenden su éxodo de Cuba a los Estados Unidos en la Operación Peter Pan después del triunfo de la Revolución Cubana, la trayectoria de su empoderamiento radical como artista-mujer latina y su experimentación estético-genérica contra muros hegemónicos dominantes sexistas, racistas y clasistas. Redfern y Caron registran el panculturalismo y el retorno de Mendieta a Cuba en los ochenta, además de anotar el prestigioso Prix de Rome y su casamiento y conflictos conyugales con Carl Andre que culminan en su muerte.

Una última escena a destacar es el montaje-instalación gráfico sobre la muerte de Mendieta en la última sección que despliega una macroviñeta tripartita ilustrando su última llamada telefónica, su violenta caída enmarcada en un globo que reza, "Mendieta abolla o marca sangrante en el techo de la deli, abajo" y una silueta amortajada con un corazón sangrante. Otra microviñeta hace palpable el cuerpo de Mendieta y audible su última súplica a Andre "No, No, No, No lo hagas", retando al lector a completar la secuencia gráfica representada (Redfern y Caron 35). El ensayo crítico original de Redfern, "Blind Spot: A Note to Readers", sitúa el biopic postmoderno sobre Ana Mendieta entre focalizaciones, intertextualidad, reciclaje, renarrativización, metanarrativa y montajes gráficos. En "Blind Spot"se conjuntan textos cortos, reportajes, crónicas, nota roja, homenajes, citas, cortes biográficos, reseñas de arte, crítica, reproducciones de obras performativas, una galería de siluetas, ilustraciones de Carolee Schneemann, Frida Kahlo y Hannah Wilke, entre otras, fragmentos periodísticos y secciones de opinión, reseñas y anotaciones postmortem, además de cortos artículos periodísticos basados en el libro Naked by the Window: The Fatal Marriage of Carl Andre and Ana Mendieta, de Robert Katz (I990).

El arte secuencial movedizo en Who Is Ana Mendieta? desnuda una complejidad estético-política postfeminista en un relato gráfico que hace eco de la geografía de Mendieta como criptograma, "desnudo femenino que actúa en el estudio, se fusiona con la naturaleza, se graba en una hoja o se quema en la tierra o en el tronco de un árbol como marca [identitaria] o firma de su producción artística" (Viso, Ana 22). La fluidez de las líneas de vida de Mendieta siendo grafía corpórea entintada se desborda entre centros y periferias de la construcción biográfica, condensa actos performativos y medioambientales y pone en relieve territorios interiores, obsesión estética y experimentación. Al Caron desparramar líneas y trazos 
en contornos verticales, rectos, curvos, quebrados, circulares y mixtos en sus ilustraciones, la composición plasma una topografía de marcas identitarias, hendiduras y cicatrices de des/territorialización del sujeto latino. Esta des/territorialización la atestigüan asimismo los filmes curados por Lynn Lukkas y Howard Oransky en Covered in Time and History: The Films of Ana Mendieta (2015) incorporando sus raíces, herencia e identidad cubana. En la piel del texto gráfico, encuadres, planos, formatos irregulares, rectangulares, ovalados y quebrados arman macroviñetas que desde ángulos de visión medios, picados y contrapicados ponen en movimiento unidades secuenciales de un tamaño menor y despliegan unidades mínimas en forma transversal, discontinua y abierta. Redfern y Caron imprimen un nomadismo artístico-genérico, sexual, étnico y político diferencial a su relato ilustrado. Sin borrar huellas histórico-referenciales, culturales, raciales, sexuales y genéricas, rellenan escenarios gráficos que sustentan al sujeto auto/biografiado entre historia, biografía, género $\mathrm{e}$ intersubjetividades, mientras desarticulan la crítica hegemónica centrada en el escándalo mórbido y amarillista del acto violento que puso fin a la vida de la artista el 8 de septiembre de 1985 .

DESENTINTAR TEXTURAS GRÁFICAS DE UN RELATO HEGEMÓNICO: TRAZOS, CONTORNOS, GESTUALIDAD

El suplemento cultural "Blind Spot" diseña marcos interpretativos que cuestionan el escándalo como centro del life-writing hegemónico, desarticulan el drama personal como proposición mórbida amarillista o de nota roja y desmontan el silogismo racializado de excesos sexuales, performativos y estéticos. Este apartado expone premisas de una narrativa conveniente sobre el trágico fin de Mendieta y despliega el cuerpo correccional que demoniza a Ana Mendieta por su latinidad, género y sexualidad, mientras señala de frente la memoria oficial de impunidad de la violencia de género. Pone en escena, contextualiza el acto violento y diseña un suplemento genérico-cultural que denuncia la violencia y el crimen de género conectando al lector gráfico íntimamente con la muerte de Ana Mendieta. Este apartado integra fragmentos bajo encabezados periodísticos como "Crime", "Community News", "Gallery" o "Postmortem", entre otros (Redfern y Caron 4I-53). En su conceptualización, las autoras redefinen las técnicas del discurso gráfico al reunir crónicas breves bajo títulos que detallan la comunidad artística de Nueva York, el portero del edificio, Andre explicándole a la policía que él era un artista famoso o la vida imitando al arte, por mencionar algunos.

Como señala Christine Redfern en este apartado, el cómic como discurso híbrido de varias fuentes digitales e impresas, manipula citas y 
textos referenciales y los reformatea. Los segmentos periodísticos suplementan comentarios breves consabidos, manufacturados o imaginados y reclaman historias no oficiales, de cultura popular, rumor, editoriales y reportajes, además de reconfigurar fragmentos de Where Is Ana Mendieta? (1999) de Jane Blocker. Enfrentan al lector gráfico al crimen/accidente cometido por William Burroughs contra su mujer en I95I, a los disparos de Valerie Solanas contra Andy Warhol en 1968 y al acuchillamiento de Norman Mailer de su esposa Adele Morales en 1960, entre otros relatos, reproducen obras de arte y realzan una galería de mujeres artistas de vanguardia (Redfern y Caron 39-40, 44-46, 46-47).

Al pensar en la inscripción de la corporeidad tanto en las obras de Mendieta como en la biográfica, no podemos dejar de considerar, como afirma el crítico Javier Guerrero, que tanto visualidad como visibilidad afectan la corporeidad en relación a formas, medios, sistemas, consumos y lecturas que movilizan más allá de las miradas vertidas sobre los cuerpos mismos (45). La geografía corpórea en la gráfica entintada hace audible la voz de Mendieta en el texto y el poema donde se nombra a sí misma escrito en $198 \mathrm{r}$ :

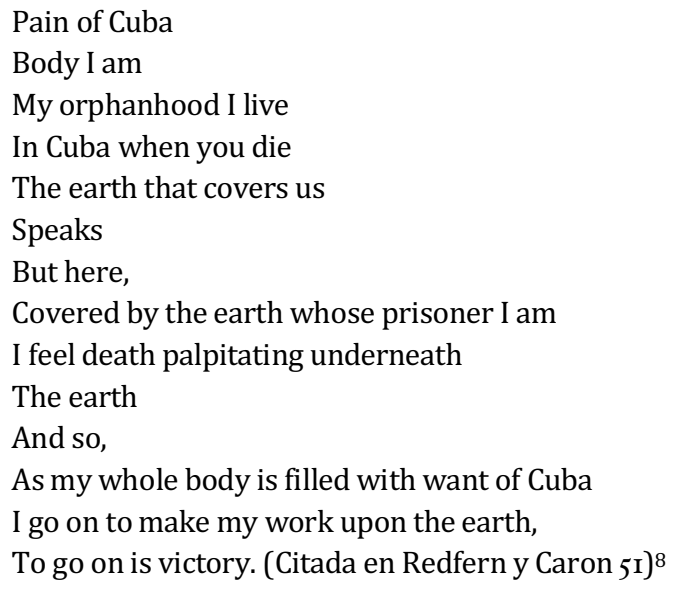

Redfern y Caron trazan la silueta de un sujeto latino bio/grafiado desde una memoria cultural disidente, imprimen huellas de género desde fronteras estético-políticas y genéricas movedizas y tejen ciudadanías, saberes y cruces transculturales que se materializan en la piel-papel de un relato gráfico entintado que nos incita a transitar otras nomadías en discursos de life-writing movedizos. 
Davidson College

\section{NOTAS}

I Christine Redfern es una reconocida artista, curadora, escritora, directora artística de video performances y crítica de arte contemporánea radicada en Montreal, con especialización en el estudio de las artes y en comunicaciones biomédicas, que ha exhibido internacionalmente sus dibujos y piezas de animación. Ha contribuido con su crítica, arte experimental y experiencia estética a nivel local, nacional e internacional al Montreal Gazette, Montreal Mirror, Canadian Art, Globe and Mail, National Post y Contemporary Magazine. Caro Caron es fundadora, curadora y directora artística de Ellephant (http://www.ellephant.org), además de ilustradora, pintora, dibujante y artista gráfica y de cómics basada en Montreal que ha publicado su obra en periódicos y en revistas como Kick Magazine, Cyclops, Aim of the Eye Album, L'Enfance du Cyclope, Montreal Mirror Special Comix Edition, Mac Tin Tac Comic Book y King Can Comix Fanzine, entre otros. Ha sido pintora de cuerpo y artista-maquillista profesional durante más de once años. Quisiera expresar mi profundo aprecio y gratitud a la Dra. Emma García, con quien tuve el privilegio de colaborar en la presentación "Trans-Nepantlista Visual Geographies and the Inked Latina Body: Who Is Ana Mendieta?", en la sesión organizada por la Dra. Hilda Chacón, Gender(ed) Performativities in Latin America and Latin@ Graphic Novels, en la I28 MLA Convención Anual de 2013. He traducido al español todas las referencias al texto gráfico con excepción de algunos subtítulos del apartado "Blind Spot: A Note to Readers", siguiendo la paginación original de Who Is Ana Mendieta?

2 Los marcos teóricos fundamentales sobre la narrativa gráfica se asientan en propuestas de Hilary H. Chute y Ana Merino, integrando marcos de las narrativas gráficas y cómics latinos, latinoamericanos y anglosajones desde el filtro del género y narrativa gráfica. Han sido fundamentales las compilaciones de textos editados por Laurie Mc Neill y Kate Douglas en $a / b$ : Autobiography Studies (2017), Héctor Fernández L'Hoeste y Juan Poblete (2009), Miriam Fusch y Craig Howes sobre Pedagogía y Life-Writing (2008), además del texto editado por Stephen E. Tabachnick (2009) y el de Michael Lackey sobre bioficciones o biografías ficticias (2016). Indispensable en todo acercamiento crítico a la obra de Ana Mendieta son los excelentes estudios monográficos de la curadora Olga Viso, Ana Mendieta: Earth Body, Sculpture and Performance, 1972-I985, Unseen Mendieta: The Unpublished Works of Ana Mendieta y el reciente estudio crítico y catálogo sobre la videofilmografía de Mendieta de su exhibición curada por Lynn Lukkas y Howard Oransky, Covered in Time and 
History: The Films of Ana Mendieta. La exhibición ha transitado por la Universidad de Minnesota (2015), el NSU Museo de Arte de Fort Lauderdale Florida (2016), el Berkeley Art Museum y el Pacific Film Archive (2016-20I7).

3 Al teorizar sobre este texto de Redfern y Caron, se hace inevitable construir un marco teórico que corresponda a la estética gráfica radicalmente feminista encarnada en esta narrativa de casi 50 páginas. El concepto de entintado gráfico como un acto performativo y estético-crítico feminista dentro de este biopic gráfico opera en distintos marcos, niveles, diseño gráfico, narración de vida y réplicas intermediales de algunas piezas performativas de Ana Mendieta como serían sus siluetas, concebidas dentro del texto como siluetas entintadas. El concepto "entintado" o INKED conlleva la acentuación intencional de Redfern y Caron de ciertos biografemas o marcadores biográficos que arman estratégicamente el cuerpo-texto entintado de Ana Mendieta, remitiéndonos al ser una artista latina, una artista de color, a su identidad y género dentro del mundo del arte hegemónico, rechazando el amarillisimo cultural del tabloide. Este vocablo remite a la documentada violencia de género y a la muerte de Mendieta, aludidas directamente en el texto. Desbordando otras narrativas críticas punzantes bajo la piel del texto gráfico, no se puede dejar de anotar la referencia a "entintado" al consumirse visualmente una metanarrativa entrehecha de "siluetas entintadas". El concepto se aplica asimismo a las piezas reproducidas de la Serie Siluetas de la artista performativa cubana en un número significativo de macroviñetas. La declaración o manifiesto de género incluido en la "Introducción" de Lucy R. Lippard, además del apartado "Blind Spot" de la crítica y artista Christine Redfern, aunados a la galería de las contraportadas del texto pobladas por figuras relevantes del mundo del arte reafirman el valor del concepto de "entintado".

4 Veáse Lucy R. Lippard, "Introduction: Who Is Ana Mendieta, Nobody Else” en Redfern y Caron Who Is Ana Mendieta? (6-15). Se seguirá la páginación de esta edición al referirnos a secciones específicas del texto, como son la introducción, y los dos apartados titulados "Blind Spot: A Note to Readers" (3940) y "Blind Spot" (4I-53), también al referirnos al texto dentro de una macroviñeta.

5 Al combinar marcos teóricos de la teoría de life-writing, teoría del biopic femenino y teoría de la autobiografía, la composición y construcción gráfica del texto sobre la artista cubana articula una serie de cuestiones teóricas que nos permiten diseñar un modelo de análisis sobre representación, encarnación, documentación e inscripción de señas de identidad que diseñan una geografía experimental en la colaboración de Redfern y Caron en esta narrativa gráfica postmoderna. Consúltense los textos indispensables de Sidonie Smith y Julia Watson, y de Leonor Arfuch, sobre teoría de life-writing y 
género, sujeto biográfico y subjetividades contemporáneas y el estudio crítico de Bronwyn Polaschek en cuanto a biografía fílmica o biopic. El estudio fundamental sobre tecnología del cuerpo en nuestra aproximación al cuerpotexto gráfico, género y sexualidades dentro del campo de estudios culturales y visuales latinoamericanos es el de Javier Guerrero, Tecnologías del cuerpo: exhibicionismo y visualidad en América Latina.

6 Consúltense teorías sobre construcción biográfica fílmica en los recientes estudios de Bronwyn Polaschek, Sidonie Smith y Julia Watson, José Quiroga y Anne Raine.

7 Centros de gravedad movedizos serían aquellos sitios del cuerpo-texto gráfico encerrados en macroviñetas que operan como nudos de significación biográfica o sitios-enunciativos de un segmento de vida de la artista cubana. Estos operan como vínculos biográficos que afectan, impulsan o movilizan el contorno del cuerpo-texto gráfico de vida. En el relato funcionarían como centros de gravedad movedizos por ejemplo en la macroviñeta de la escena del performance de la violación y en el performance-réplica de la escena de la violación en la parte superior del lado derecho de la macroviñeta. Como centros gravitacionales producen otros hilos narrativos en escena como son la documentación y filmación de la escena, la inclusión de una audiencia frente al acto performativo y el registro de la figura de Mendieta haciendo declaraciones sobre la violencia sexual. Al mismo tiempo, remiten a información específica sobre violencia doméstica, violación y crimen en el campus universitario. El centro de gravedad en la parte izquierda inferior incorpora la figura de un crítico de arte que articula un comentario sobre el mercado del arte, el consumo estético del escándalo, elementos de comercialización de la obra de arte, consejos sobre formas de sexualizarla, empacarla e hiperdramatizar el escándalo de la violación, o el crimen sexual para el consumo público (Redfern y Caron 28).

8 Veáse este poema incluido en la sección de "Blind Spot" titulada "Insight", en donde aparece una nota biográfica sobre su afiliación al programa de Intermedia en Iowa en 1972, una nota breve sobre violencia de género televisiva, fílmica y en juegos computacionales, una referencia al amorío de Carl Andre en 1984, la reproducción de la fotografía del casamiento de Ana Mendieta y Carl Andre el 17 de enero de 1985 en Roma, Italia, una nueva obra por encargo del Otis Art Institute del Parsons School of Design y una nota de Julian Schnabel (Redfern y Caron 5r).

\section{OBRAS CITADAS}

A RF U CH, LEO NOR. El espacio biográfico: dilemas de la subjetividad contemporánea. Buenos Aires: Fondo de Cultura Económica, 20 Io. 
-. Memoria y autobiografía: Exploraciones en los límites. México: Fondo de Cultura

Económica, 2013.

Blocker, Jane. Where Is Ana Mendieta? Identity, Performativity, and Exile.

Durham: Duke UP, 1999.

Ch U te, hi l Lar y L. Graphic Women: Life Narrative and Contemporary Comics. New

York: Columbia UP, 2OIO.

Drake, Jennifer. "Embracing the Surface: How to Read a Life Narrative." Eds.

Laurie McNeill y Kate Douglas. Teaching Lives: Contemporary Pedagogies of

Life Narratives. a/b: Autobiography Studies 32.I (2017): 67-74.

fernandez l' ho ste, héctor, y juan po вlete. Redrawing the Nation: National

Identity in Latin/o American Comics. New York: Palgrave Macmillan, 2009.

FUChS, MiRiam, y CRAig howes. Introduction. Teaching Life-Writing Texts. New

York: The Modern Language Association of America, 2008. I-I9.

G U R R ER Ro, JAVIER. Tecnologías del cuerpo: Exhibicionismo y visualidad en América

Latina. Madrid: Iberoamericana/Rice University, 2015.

gumbrecht, hans-ulrich. "Why Intermediality If At All?" Intermedialidad $e$

hispanística. Ed. Angelica Rieger. Frankfurt: Peter Lang, 2003. I3-I8.

HELMS, GABRIELE. "The Generic Instability of Contemporary Life Writing in

Canada." Teaching Life Writing Texts. Eds. Miriam Fuchs y Craig Howes. New

York: The Modern Language Association of America, 2008. 99-106.

howes, CRAig. "Biography, Oral History, Autobiography: A Graduate Course.

Introduction." Teaching Life-Writing Texts. Eds. Miriam Fusch y Craig Howes.

New York: The Modern Language Association of America, 2008. II5-21.

катZ, вове тт. Naked by the Window: The Fatal Marriage of Carl Andre and Ana

Mendieta. New York: Atlantic Monthly P, r990.

Lackey, michael. "Locating and Defining the Bio in Biofiction." Life Narratives

Biofictions, a/b: Auto/Biography Studies 31.I (2016): 3-10.

LIPPARD, LUCY R. "Who Is Ana Mendieta/Nobody Else." Redfern y Caron. 6-I5.

LUKKAS, LYNN, y hOWARD ORANSKY, EDs. Covered in Time and History: The Films

of Ana Mendieta. Minneapolis and Berkeley: U of Minnesota, and U of California $\mathrm{P}, 2015$.

mCneill, laurie, y Kate douglas, eds. "Heavy Lifting: The Pedagogical Work of

Life Narratives." Teaching Lives: Contemporary Pedagogies of Life Narratives.

a/b: Autobiography Studies 32.I (2017): 5-I4.

m Endet A, An A. Covered in Time and History: The Films of Ana Mendieta. February

28-July 3, 20I6. NSU Art Museum. Fort Lauderdale.

MERIN 0, ANA. El cómic hispánico. Madrid: Cátedra, 2005.

PO LASCHE к, в O NWyn. The Postfeminist Biopic: Narrating the Lives of Plath,

Kahlo, Woolf and Austen. New York: Palgrave Macmillan, $20 \mathrm{I} 3$.

Q U I Ro GA, José. Cuban Palimpsests. Minneapolis: U of Minnesota P, 2005. 
redfern, Christine, y Caro Caron. Who Is Ana Mendieta? New York: Feminist $\mathrm{P}, 2 \mathrm{OII}$.

REINE, AN . "Embodied Geographies: Subjectivity and Materiality in the Work of Ana Mendieta." Generations and Geographies in the Visual Arts: Feminist Readings. Ed. Griselda Pollock. London: Routledge, 1996. 228-249.

S mith, Sid oniE. "Identity's Body." Autobiography and Postmodernism. Eds. Kathleen Asher, Leigh Gilmore y Gerald Peters. Amherst: The U of Massachusetts P, 1994. 266-292.

Smith, Sidonie, y JULia WATSon. "Mapping Women's Self-Representation at Visual/Textual Interfaces." Interfaces: Women, Autobiography, Image, Performance. Eds. Sidonie Smith y Julia Watson. Ann Arbor: The U of Michigan P, 2005. I-46.

TA B A CH n I K, ste Phen Ely, ed. Teaching the Graphic Novel. New York: Modern Language Association, 2009.

viso, o l g A. Ana Mendieta: Earth Body: Sculpture and Performance, 1972-1985. Washington: Hirshhorn Museum and Sculpture Garden, Smithsonian Institution, 2004.

-. Unseen Mendieta: The Unpublished Works of Ana Mendieta. Munich: Prestel, 2008. 